\title{
LEGISLAÇÃO APLICADA AO LICENCIAMENTO AMBIENTAL DE ATERROS SANITÁRIOS
}

\author{
Ricardo de Sousa Carneiro - ricardo.carneiro.mt@ gmail.com \\ Universidade Federal de Mato Grosso \\ Emanuelly Veronica Soares Leoncio - manuleoncio01@ hotmail.com \\ Universidade Federal de Mato Grosso \\ Rafaela de Araújo Costa - rafaela_araujocosta@ hotmail.com \\ Universidade Federal de Mato grosso \\ Dempsey Thrweyce Alves da Silva - dempsey_alves@ hotmail.com \\ Universidade Federal de Mato grosso
}




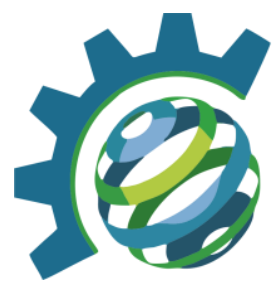

\section{RESUMO}

No Brasil, a disposição final ambientalmente adequada dos resíduos sólidos em aterros sanitários é preconizada pela Lei Federal $N^{\circ} 12.305$, de 02 de agosto de 2010, que institui a Política Nacional de Resíduos Sólidos. Conforme a Resolução CONAMA No 237 de 19 de dezembro de 1997, a localização, construção, instalação, ampliação, modificação e operação de empreendimentos e atividades consideradas efetiva ou potencialmente poluidoras, bem como os empreendimentos capazes, sob qualquer forma, de causar degradação ambiental, dependerão de prévio licenciamento do órgão ambiental competente. Os critérios e diretrizes para o licenciamento ambiental de aterros sanitários de pequeno porte, aqueles cuja disposição diária é de até 20 ton. por dia, são definidos pela Resolução CONAMA No 404, de 11 de Novembro de 2008. Para aterros sanitários com disposição diária superior a 20 ton. o licenciamento ambiental deve ser precedido da elaboração do EIA Estudo de Impacto Ambiental e do respectivo RIMA - Relatório de Impacto Ambiental. Em Mato Grosso, o licenciamento ambiental dos aterros sanitários, bem como a avaliação dos estudos e critérios ambientais para localização deste empreendimento é de responsabilidade da Secretaria de Estado do Meio Ambiente - SEMA/MT. A aprovação do EIA/RIMA e realização de audiências públicas para tomadas de decisão é de responsabilidade do Conselho Estadual do Meio Ambiente - CONSEMA. Este trabalho objetiva apresentar a legislação, normas e roteiros técnicos aplicados ao licenciamento ambiental de aterros sanitários em Mato Grosso.

Palavras-chave: Licenciamento, Resíduos sólidos, aterros sanitários.

\section{INTRODUÇÃO/OBJETIVO}

No Brasil, a produção diária de resíduos sólidos urbanos por habitante é de 1 quilograma, segundo a Associação Brasileira de Empresas Públicas e Resíduos Especiais ABRELPE. De acordo com o Instituto Brasileiro de Geografia e Estatística - IBGE, em uma estimativa realizada para 2009, a população de Cuiabá é de aproximadamente 560.000 habitantes. Nesta capital tem-se uma produção que varia de 0,6 a 0,9 quilogramas por habitante/dia, um pouco inferior à média na nacional. A cidade de Cuiabá produz diariamente cerca de 530 toneladas de resíduos domiciliares. De acordo com Ensinas (2003), a disposição final dos resíduos sólidos urbanos é um dos graves problemas ambientais enfrentados pelos grandes centros urbanos em todo o planeta.

O licenciamento ambiental é uma obrigação legal prévia à instalação de qualquer empreendimento ou atividade potencialmente poluidora ou degradadora do meio ambiente. Essa obrigação é compartilhada pelos Órgãos Federais, Estaduais e Municipais de Meio Ambiente, como partes integrantes do SISNAMA (Sistema Nacional de Meio Ambiente).

A Resolução do CONAMA (Conselho Nacional do Meio Ambiente) No 237, de 19 de Dezembro de 1997, nos respectivos incisos do Art. $1^{\circ}$ define:

I - Licenciamento Ambiental: procedimento administrativo pelo qual o órgão ambiental competente licencia a localização, instalação, ampliação e a operação de empreendimentos e atividades utilizadoras de recursos ambientais, consideradas efetiva ou potencialmente poluidoras ou daquelas que, sob qualquer forma, possam causar degradação ambiental, considerando as disposições legais e regulamentares e as normas técnicas aplicáveis ao caso. 
II - Licença Ambiental: ato administrativo pelo qual o órgão ambiental competente, estabelece as condições, restrições e medidas de controle ambiental que deverão ser obedecidas pelo empreendedor, pessoa física ou jurídica, para localizar, instalar, ampliar e operar empreendimentos ou atividades utilizadoras dos recursos ambientais consideradas efetiva ou potencialmente poluidoras ou aquelas que, sob qualquer forma, possam causar degradação ambiental.

Os critérios e diretrizes para o licenciamento ambiental de aterros sanitários de pequeno porte, aqueles cuja disposição diária é de até 20 ton. por dia, são definidos pela Resolução CONAMA No 404, de 11 de Novembro de 2008. Para aterros sanitários com disposição diária superior a 20 ton. O licenciamento ambiental deve ser precedido da elaboração do EIA - Estudo de Impacto Ambiental e do respectivo RIMA - Relatório de Impacto Ambiental, cujos critérios básicos e as diretrizes gerais são definidos pela Resolução CONAMA No 001, de 23 de janeiro de 1986.

Diante de tal situação, esse trabalho tem por objetivo apresentar as resoluções e normas técnicas que definem as condições mínimas exigíveis para projeto, implantação e operação de aterros sanitários e exibir os roteiros técnicos que referenciam o estudo de alternativas locacionais para sistema de tratamento, disposição final de resíduos sólidos urbanos e licenciamento ambiental de aterros sanitários.

\section{METODOLOGIA}

Para execução desse estudo, realizaram-se pesquisas em resoluções e normas referentes à temática de resíduos sólidos e meio ambiente. Estruturou-se a pesquisa em fundamentação legal, onde foram descritos as funções dos órgãos competentes e a apresentação da legislação; e então se apresentou os critérios e roteiros.

Na fundamentação legal foram abordados os seguintes temas: Política Nacional de Meio Ambiente, Política Nacional de Resíduos Sólidos, Conselho Nacional do Meio Ambiente - CONAMA, Associação Brasileira de Normas Técnicas - ABNT, Conselho Estadual do Meio Ambiente - CONSEMA e Secretaria de Estado do Meio Ambiente de Mato Grosso - SEMA/MT.

\section{RESULTADOS E DISCUSSÃO}

\subsection{Fundamentação legal}

- Política Nacional de Meio ambiente:

A Lei $\mathrm{N}^{\circ}$ 6.938, de 31 de agosto de 1981, com base nos incisos VI e VII do Art. 23 e no Art. 225 da Constituição, estabelece a Política Nacional de Meio ambiente com o objetivo de preservar, melhorar e recuperar a qualidade ambiental do país através do SISNAMA (Sistema Nacional de Meio Ambiente).

O SISNAMA é um sistema que congrega órgãos públicos das esferas federal, estadual e municipal, incluindo o Distrito Federal, da seguinte maneira:

- O Conselho de Governo é o órgão superior do SISNAMA e o responsável por assessorar o Presidente da República na formulação de diretrizes para a Política Nacional de Meio Ambiente;

- CONAMA, ou Conselho Nacional de Meio Ambiente, é o órgão consultivo e deliberativo do SISNAMA que estabelece parâmetros federais (normas, resoluções e padrões) a serem obedecidos pelos Estados. 


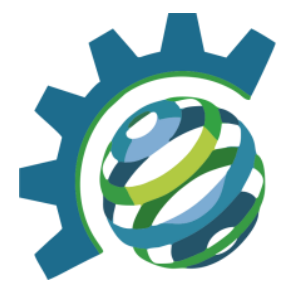

- Ministério do Meio Ambiente (MMA) é o órgão responsável pelo planejamento, coordenação, controle e supervisão da Política Nacional de Meio Ambiente.

- Instituto Brasileiro de Meio Ambiente e dos Recursos Naturais Renováveis (IBAMA) é o órgão executor, responsável por formular, coordenar, fiscalizar, executar e fazer executar a Política Nacional de Meio Ambiente sob os auspícios do MMA.

- Os Órgãos Seccionais são as entidades de cada Estado da Federação responsáveis por executar programas e projetos de controle e fiscalização das atividades potencialmente poluidoras.

- E, por fim, os órgãos locais, ou municipais, que são os responsáveis por atividades de controle e fiscalização das atividades potencialmente poluidoras.

A Política Nacional define o meio ambiente como sendo um patrimônio público que, portanto, que deve ser protegido e justifica a racionalização do uso do solo, subsolo, água e ar. Além de planejamento e fiscalização dos recursos naturais, proteção dos ecossistemas, controle e zoneamento das atividades poluidoras, incentivo às pesquisas com este intuito, recuperação de áreas degradadas e educação ambiental em todos os níveis de ensino.

Para tal, a Lei N. ${ }^{\circ} 6.938$ institui alguns instrumentos com os quais visa garantir o alcance de seus objetivos: o estabelecimento de padrões de qualidade ambiental, zoneamento ambiental, avaliação de impactos ambientais (AIA), licenciamento e fiscalização ambientais, incentivos às tecnologias limpas, criação de unidades de conservação, criação de um sistema nacional de informações ambientais, um cadastro técnico federal de atividades e instrumentos de defesa, penalidades disciplinares ou compensatórias e um relatório de qualidade do meio ambiente.

- Política Nacional de Resíduos sólidos:

A Lei $n^{\circ} 12.305 / 10$, regulamentada pelo Decreto $n^{\circ} 7.404 / 2010$ que institui a Política Nacional de Resíduos Sólidos (PNRS) contém instrumentos importantes relacionados a implantação e gerenciamento dos aterros sanitários.

Propõe que até 2014 os lixões sejam erradicados no país. Prevê a prevenção e a redução na geração de resíduos, tendo como proposta a prática de hábitos de consumo sustentável e um conjunto de instrumentos para propiciar o aumento da reciclagem e da reutilização dos resíduos sólidos (aquilo que tem valor econômico e pode ser reciclado ou reaproveitado) e a destinação ambientalmente adequada dos rejeitos (aquilo que não pode ser reciclado ou reutilizado). Cria uma meta importante que é de alcançar o índice de reciclagem de resíduos de $20 \%$ em 2015.

- Conselho Nacional do Meio ambiente - CONAMA:

O Conselho Nacional do Meio Ambiente - CONAMA é o órgão consultivo e deliberativo do Sistema Nacional do Meio Ambiente-SISNAMA, foi instituído pela Lei 6.938/81, que dispõe sobre a Política Nacional do Meio Ambiente, regulamentada pelo Decreto 99.274/90. São atos do CONAMA: Resoluções, quando se tratar de deliberação vinculada a diretrizes e normas técnicas, critérios e padrões relativos à proteção ambiental e ao uso sustentável dos recursos ambientais; Moções, quando se tratar de manifestação, de qualquer natureza, relacionada com a temática ambiental; Recomendações, quando se tratar de manifestação acerca da implementação de políticas, programas públicos e normas com repercussão na área ambiental, inclusive sobre os termos de parceria de que trata a Lei no 9.790, de 23 de março de 1999; Proposições, quando se tratar de matéria ambiental a ser encaminhada ao Conselho de Governo ou às Comissões do Senado Federal e da Câmara dos Deputados; Decisões, quando se tratar de multas e outras penalidades impostas pelo IBAMA, 


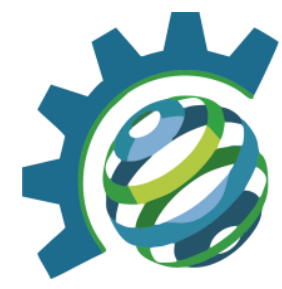

em última instância administrativa e grau de recurso, por meio de deliberação da Câmara Especial Recursal - CER.

- Associação Brasileira de Normas Técnicas - ABNT:

A Associação Brasileira de Normas Técnicas (ABNT) é o órgão responsável pela normalização técnica no país, fornecendo a base necessária ao desenvolvimento tecnológico brasileiro. É uma entidade privada, sem fins lucrativos, reconhecida como único Foro Nacional de Normalização através da Resolução n. ${ }^{\circ} 07$ do CONMETRO, de 24.08.1992.

- Conselho Estadual do Meio Ambiente - CONSEMA:

O CONSEMA, Órgão Colegiado do Sistema Estadual do Meio Ambiente (SIMA), tem por finalidades assessorar, avaliar e propor ao Governo do Estado de Mato Grosso diretrizes da Política Estadual do Meio Ambiente, bem como deliberar, no âmbito de sua competência, sobre normas e padrões compatíveis com um meio ambiente ecologicamente equilibrado e essencial à qualidade de vida.

Compete ao CONSEMA exercer as competências previstas no art. $3^{\circ}$, incisos I a XVI da Lei Complementar $n^{\circ} 38$, de 21 de novembro de 1995, alterada pela Lei Complementar $n^{\circ}$ 232, de 21 de dezembro de 2005. Algumas dessas competências são:

I - participar da elaboração da Política Estadual do Meio Ambiente, inclusive mediante a proposição de normas e diretrizes que excedam ao seu nível de competência;

II - aprovar normas definindo padrões de qualidade ambiental e de emissões, bem como as relativas ao uso racional dos recursos ambientais;

III - aprovar normas regulamentadoras, do ponto de vista da proteção ambiental e da saúde pública, da legislação relativa ao uso, transporte e comercialização de produtos tóxicos ou perigosos;

IV - apreciar e deliberar sobre o licenciamento ambiental de projetos públicos e ou privados que impliquem na realização do Estudo de Impacto Ambiental - RIMA, designando, para tanto, três de seus membros;

V - Deliberar sobre a dispensa do Estudo de Impacto Ambiental, para atividades elencadas no art. 24, mediante recomendação da SEMA;

VI - participar, obrigatoriamente, das audiências públicas convocadas para a apresentação de projetos e discussão do respectivo relatório de Impacto Ambiental - RIMA, designando, para tanto, três de seus membros.

- Secretaria de Estado do Meio Ambiente - SEMA/MT:

O DECRETO $\mathrm{N}^{\circ}$ 2.484, DE 15 DE ABRIL DE 2010, que aprova o Regimento Interno da Secretaria de Estado de Meio Ambiente - SEMA atribui a Coordenadoria de Gestão de Resíduos Sólidos:

Art. 27. - A Coordenadoria de Gestão de Resíduos Sólidos tem como missão promover a melhor adequação ambiental no trato, transporte, modificação e armazenamento dos resíduos sólidos e sua regularização, competindo-lhe:

I - coordenar os trabalhos relativos ao monitoramento e licenciamento ambiental, das atividades inerentes a resíduos sólidos; 
II - propor normas de estabelecimento de padrões de controle dessas atividades;

III - verificar o cumprimento das obrigações ambientais impostas através de notificações, termos de ajustamento de condutas, planos de recuperação de áreas degradadas e outros;

IV - manter um cadastro atualizado dos projetos e empreendimentos de atividades geradoras de resíduos sólidos e seus respectivos licenciamentos;

V - propor aplicação de medidas de compensação ambiental para atividades geradoras de resíduos sólidos os com efetiva ou potencial capacidade nociva ao meio ambiente.

A Gerência de Gestão de Resíduos Sólidos Industriais e Agrícolas:

Art. 28. A Gerência de Gestão de Resíduos Sólidos Industriais e Agrícolas tem como missão promover o monitoramento e licenciamento ambiental das atividades geradoras de resíduos sólidos em atividades industriais e agrícolas, competindo-lhe:

I - Gerenciar a execução do licenciamento, controle e monitoramento das atividades geradoras de resíduos sólidos em atividades industriais e agrícolas;

II - Subsidiar as análises dos planos de gerenciamento de resíduos sólidos industriais e agrícolas;

III - realizar perícias e auditorias quando solicitada nos estabelecimentos e atividades referentes à área de atuação da gerencia.

A Gerência de Resíduos Urbanos e Hospitalares:

Art. 29. A Gerência de Resíduos Urbanos e Hospitalares tem como missão promover o monitoramento e licenciamento ambiental das atividades geradoras de resíduos sólidos no meio urbano e advindas dos serviços de saúde, competindo-lhe:

I - Gerenciar a execução do licenciamento, controle e monitoramento das atividades geradoras de resíduos sólidos advindos dos serviços de saúde no meio urbano e advindas dos serviços de saúde;

II - Subsidiar as análises dos planos de gerenciamento de resíduos sólidos no meio urbano e advindos dos serviços de saúde.

\subsection{Resolução CONAMA}

A resolução CONAMA n ${ }^{\circ}$ 404, de 11 de novembro de 2008 estabelece critérios e diretrizes para o licenciamento ambiental de aterros de pequeno porte responsáveis por resíduos sólidos urbanos.

Nos aterros sanitários de pequeno porte é admitida a disposição final de resíduos sólidos domiciliares, de resíduos de serviços de limpeza urbana, de resíduos de serviços de saúde, bem como de resíduos sólidos provenientes de pequenos estabelecimentos comerciais, industriais e de prestação de serviços.

Esses resíduos não devem ser perigosos, conforme definido em legislação específica, e devem ter características similares aos gerados em domicílios, bem como aos resíduos de serviços de saúde que não requerem tratamento prévio à disposição final, de acordo com a 


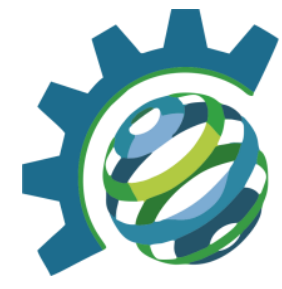

regulamentação técnica dos órgãos de saúde e de meio ambiente, conforme RDC Anvisa 306/2004 e Resolução Conama no 358/2005.

Não podem ser dispostos nos aterros sanitários os resíduos perigosos que, em função de suas características de inflamabilidade, corrosividade, reatividade, toxicidade, carcinogenicidade, teratogenicidade, mutagenicidade e perfurocortantes, apresentem risco à saúde pública e ao meio ambiente, bem como os resíduos da construção civil, os provenientes de atividades agrosilvopastoris, dos serviços de transportes, de mineração de serviço de saúde classificados na RDC Anvisa 306/2004 e Resolução CONAMA no 385/05 com exigência de destinação especial.

\subsection{Normas ABNT}

Os parâmetros e faixas de recomendações para o dimensionamento de unidades componentes de um projeto de resíduos sólidos e respectivo aterro sanitário estão disponíveis nas normas brasileiras editadas pela Associação Brasileira de Normas Técnicas (ABNT). Principais normas da Associação Brasileira de Normas Técnicas (ABNT) relativas a resíduos sólidos e limpeza urbana:

- NBR 10.007 -Amostragem de resíduos;

- NBR 8.419 -Apresentação de projetos de aterros sanitários de resíduos sólidos urbanos;

- NBR 11.174 -Armazenamento de resíduos classes II - Não inertes e III - Inertes;

- NBR 12.235 -Armazenamento de resíduos sólidos perigosos;

- NBR 13.896 -Aterros de resíduos não perigosos - critérios para projetos, implantação e operação - procedimento;

- NBR 12.810 -Coleta de resíduos de serviços de saúde;

- NBR 13.463-Coleta de resíduos sólidos;

- NBR 12.980 -Coleta, varrição e acondicionamento de resíduos sólidos urbanos;

- NBR 12.988 -Líquidos livres - verificação em amostra de resíduos. (Ensaio);

- NBR 10.005 -Lixiviação de resíduos. (Procedimento);

- NBR 12.809 -Manuseio de resíduos de serviços de saúde. (Procedimento);

- NBR 12.808 -Resíduos de serviços de saúde. (Procedimento);

- NBR 12.807 -Resíduos de serviços de saúde. (Classificação);

- NBR 10.004- Resíduos sólidos. (Classificação);

- NBR 10.006-Solubilização de resíduos. (Procedimento);

- NBR 13.221- Transporte de resíduos. (Procedimento);

\subsection{Resolução CONSEMA}

Os aterros sanitários com capacidade superior a 100 ton/dia, segundo a Resolução CONSEMA $\mathrm{N}^{\circ}$ de 16 de 20 de agosto de 1996, deverão apresentar o Estudo de Impacto Ambiental e respectivo Relatório de Impacto a Meio Ambiente (EIA/RIMA). Esta exigência embasa-se no Parágrafo único do Art. $2^{\circ}$ da Resolução CONAMA No 404: O órgão ambiental competente, verificando que o aterro proposto é potencialmente causador de significativa degradação do meio ambiente, exigirá EIA/RIMA.

A elaboração do EIA/RIMA deve seguir um Termo de Referência a ser expedido pela Coordenadoria de Avaliação de Impactos Ambientais em conjunto com a Coordenadoria de Gestão de Resíduos Sólidos da Secretaria de Estado do Meio Ambiente - SEMA/MT. 
Compõe o Termo de Referência: contexto do projeto, diagnóstico ambiental da área de influência, descrição do projeto, prognóstico dos impactos ambientais, descrição da área impactada, medidas mitigadoras e compensatórias e planos de acompanhamento e monitoramento. Anexo a este trabalho encontra-se o Termo de Referência para elaboração de estudo de impacto ambiental e relatório de impacto ao meio ambiente relacionados ao sistema de tratamento e/ou disposição final de resíduos sólidos urbanos e de saúde de Cuiabá, elaborado em 2012.

\subsection{Relatórios SEMA}

A instalação de um aterro sanitário em Mato Grosso deve ser precedida de estudos de alternativas locacionais definidos em roteiro técnico da SEMA/MT. O roteiro é utilizado para licenciamento ambiental de Sistema de Tratamento e/ou Disposição final de Resíduos Sólidos (aterros sanitários) de até 20 toneladas/dia, conforme Resolução CONAMA nº . 404/2008.

Devem ser apresentados estudos viabilidade e justificativas em três áreas. Devem ser considerados no mínimo os seguintes critérios técnicos na indicação de todas as alternativas locacionais:

Tabela 2 - Critérios e justificativas para escolha de área para instalação de aterros sanitários.

\begin{tabular}{ll}
\hline Critério & Justificativa/Observações \\
\hline Distância de & Deverá ser tomada uma distância mínima para corpos d'água de \\
corpos d'água & $\begin{array}{l}100 \mathrm{~m} \text { (cem metros) em áreas urbanas e de } 200 \mathrm{~m} \text { (duzentos metros) } \\
\text { em área rural, respeitando a área de preservação permanente destes }\end{array}$ \\
& corpos d'água, conforme Lei Complementar Estadual $\mathrm{n}^{\circ} 384$, de \\
& $19 / 01 / 2010$.
\end{tabular}

Distância de Deverá ser tomada uma distância mínima para o centro geométrico aeródromos de aeródromos de $20 \mathrm{~km}$ para os operados por instrumento, e de $13 \mathrm{~km}$ para os demais, conforme resolução Conama 04/95.

Legislação A legislação do município em estudo devera ser analisada, já que há a municipal possibilidade da existência de leis municipais pertinentes ao assunto, inclusive mais restritivas que as de âmbito Estadual e/ou Federal.

Distância a A distância do centro gerador de resíduos ao empreendimento não centros ultrapasse a $20 \mathrm{~km}$, e para acesso não pavimentado não ultrapasse a urbanos ou $10 \mathrm{~km}$. Deverá obrigatoriamente ser tomada uma distância mínima de núcleos $\quad 2.000 \mathrm{~m}$ para núcleos urbanos (bairros, comunidades e distritos) e de habitacionais $500 \mathrm{~m}$ para residências isoladas (sítios, chácaras, fazendas, etc).

Distância de A intensidade de certos impactos ambientais como ruídos odores e vias públicas. modificação da paisagem, dependem diretamente da distância da fonte poluidora em relação ao receptor. Por isso, deverá ser tomada uma distância mínima de $100 \mathrm{~m}$ entre vias publicas e o empreendimento.

Direção dos A localização da área não deve possibilitar o transporte de poeiras, odores e vetores para as comunidades ou atividades econômicas 


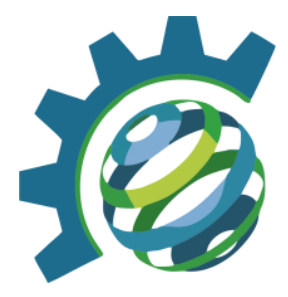

ventos incompatíveis com o empreendimento.

Dimensões da Vários são os critérios que influenciam na estimativa do tamanho da área. área necessária para implantação do empreendimento. Porém a vida útil do aterro sanitário, o seu arranjo e a quantia de resíduos que se pretende dispor são fatores determinantes nesta estimativa. Para verificação deste critério, deverá ser considerada uma vida útil do aterro sanitário de no mínimo 15 anos. Caso a alternativa locacional esteja em zona rural, há obrigatoriedade da previsão de área de reserva legal.

Profundidade Deverão ser indicadas áreas onde o nível máximo alcançado pelas de águas águas subterrâneas (medido no final do período chuvoso) seja subterrâneas. profundo, de forma que a menor distância vertical entre o supracitado nível e a superfície inferior do aterro sanitário não seja inferior á $3 \mathrm{~m}$.

Após análise das alternativas locacionais, com o aceite da melhor opção para instalação do aterro sanitário, aplica-se os roteiros de licenciamento ambiental dividido em três licenças (Licença Prévia, Licença de Instalação e Licença de Operação), conforme Art. $8^{\circ}$ da Resolução CONAMA 237:

I - Licença Prévia (LP) - concedida na fase preliminar do planejamento do empreendimento ou atividade aprovando sua localização e concepção, atestando a viabilidade ambiental e estabelecendo os requisitos básicos e condicionantes a serem atendidos nas próximas fases de sua implementação;

II - Licença de Instalação (LI) - autoriza a instalação do empreendimento ou atividade de acordo com as especificações constantes dos planos, programas e projetos aprovados, incluindo as medidas de controle ambiental e demais condicionantes, da qual constituem motivo determinante;

III - Licença de Operação (LO) - autoriza a operação da atividade ou empreendimento, após a verificação do efetivo cumprimento do que consta das licenças anteriores, com as medidas de controle ambiental e condicionantes determinados para a operação.

Nos roteiros são exigidos os documentos administrativos e documentos técnicos com apresentação dos critérios de projetos de implantação do aterro sanitário.

\section{CONCLUSÕES/RECOMENDAÇÕES}

Neste trabalho foram apresentadas as definições e caracterizações de resíduos sólidos e aterros sanitários segundo a literatura e Normas da ABNT.

Foram apresentadas as resoluções e normas técnicas que definem as condições mínimas exigíveis para projeto, implantação e operação de aterros sanitários bem como os roteiros técnicos que referenciam o estudo de alternativas locacionais para sistema de tratamento e disposição final de resíduos sólidos urbanos e licenciamento ambiental de aterros sanitários em Mato Grosso. Foram abordados também os critérios e diretrizes estabelecidos para apresentação e análise de EIA/RIMA para implantação de aterros sanitários. 

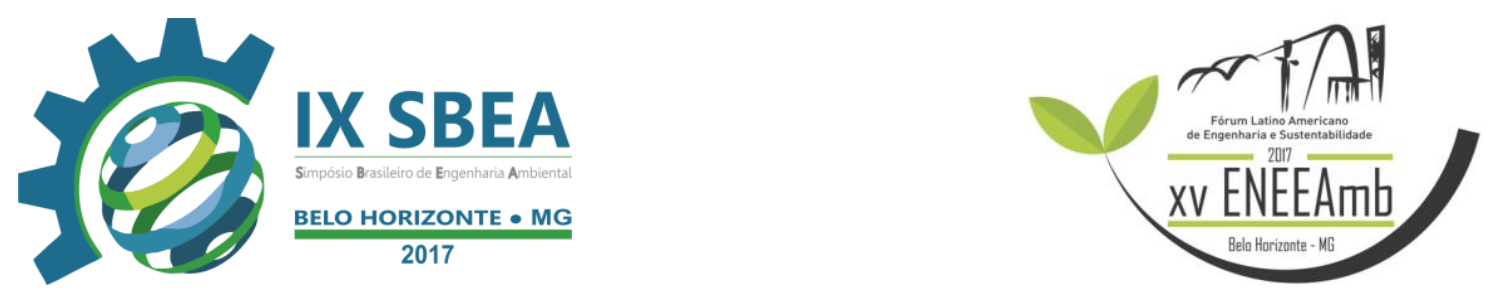

Este estudo contribuiu com a apresentação dos critérios técnicos estabelecidos em normas e legislação que norteiam a instalação e licenciamento de aterros sanitários. $\mathrm{O}$ cumprimento destes quesitos é essencial para o correto gerenciamento dos resíduos sólidos urbanos dos municípios.

\section{REFERÊNCIAS BIBLIOGRÁFICAS}

ASSOCIAÇÃO BRASILEIRA DE NORMAS TÉCNICAS. NB-842: Apresentação de projetos de aterros de resíduos industriais perigosos. Rio de Janeiro, 1983.

ASSOCIAÇÃO BRASILEIRA DE NORMAS TÉCNICAS. NBR 10004: Resíduos sólidos. Rio de Janeiro, 1987.

ASSOCIAÇÃO BRASILEIRA DE NORMAS TÉCNICAS. NBR 10157: Aterros de resíduos perigosos - Critérios para projeto, construção e operação. Rio de Janeiro, 1987.

ASSOCIAÇÃO BRASILEIRA DE NORMAS TÉCNICAS. NBR 12980: Coleta, varrição e acondicionamento de resíduos sólidos urbanos. Rio de Janeiro, 1993.

ASSOCIAÇÃO BRASILEIRA DE NORMAS TÉCNICAS. NBR 13896: Aterros de resíduos não perigosos - Critérios para projeto, implantação e operação. Rio de Janeiro, 1997.

ASSOCIAÇÃO BRASILEIRA DE NORMAS TÉCNICAS. NBR 8419: Apresentação de projetos de aterros sanitários de resíduos sólidos urbanos. Rio de Janeiro, 1984.

Brasil. 2010. Lei no 12305 de 2 de agosto de 2010. Institui a Política Nacional de Resíduos Sólidos no Brasil. Diário Oficial da União, Brasília-DF, 02 de agosto de 2010.

Brasil. 2011. Decreto n0 7404 de 23 de dezembro de 2010. Regulamenta os dispositivos da Lei 12305 de 02 de agosto de 2010. Diário Oficial da União, Brasília-DF, 02 de janeiro de 2011.

CONAMA (Conselho Nacional do Meio Ambiente). 1997. Resolução N0 237/97 - Critérios para o Licenciamento Ambiental. Brasília - DF, 19 de dezembro de 1997.

CONSELHO NACIONAL DO MEIO AMBIENTE. Resolução N. ${ }^{\circ}$ 04, de 09 de outubro de 1995. Estabelece as Àreas de Segurança Aeroporturária - ASAs. Diário Oficial da República Federativa do Brasil, 11 dez., 1995.

ENSINAS, A.V. Estudo da geração de biogás no aterro sanitário Delta em Campinas - SP. 2003. Dissertação (Mestrado em Engenharia Mecânica) - Faculdade de Engenharia Mecânica, Universidade Estadual de Campinas, Campinas, 2003.

SEMA/MT. Secretaria de Estado do Meio Ambiente. www.sema.mt.gov.br. Acesso em julho/2013. 

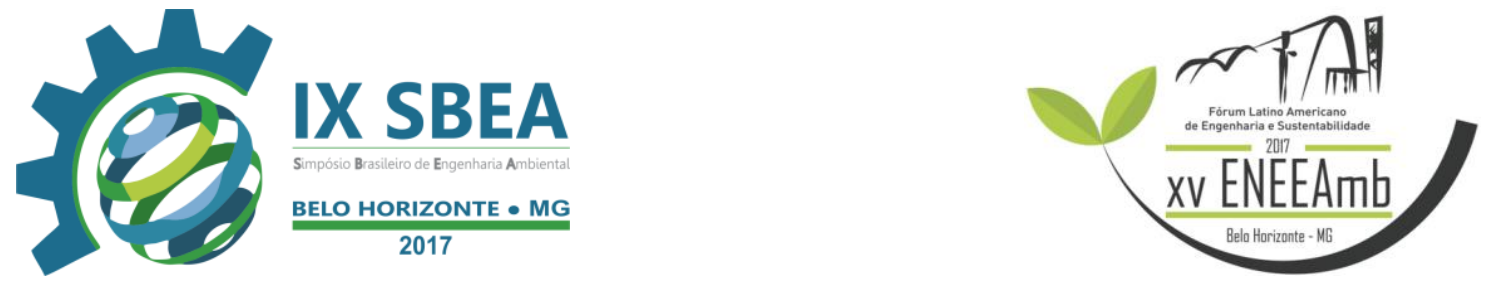

ASSOCIAÇÃO BRASILEIRA DE EMPRESAS DE LIMPEZA PÚBLICA E RESÍDUOS ESPECIAIS (ABRELPE). Panorama dos resíduos sólidos no Brasil 2010. São Paulo: ABRELPE, 2010.

IBGE - Instituto Brasileiro de Geografia e Estatística - Disponível em: (www.ibge.gov.br). Acesso em: 22 de abril de 2017.

CONAMA (Conselho Nacional do Meio Ambiente). 2008. Resolução N0 404/08 - Critérios e diretrizes para o Licenciamento Ambiental de aterro sanitário de pequeno porte de resíduos sólidos urbanos. Brasília - DF, 11 de novembro de 2008.

CONAMA (Conselho Nacional do Meio Ambiente). 1986. Resolução N0 001/86 - Critérios básicos e diretrizes para a Avaliação de Impacto Ambiental. Brasília - DF, 23 de janeiro de 1986. 